\title{
Quality of life in long-term survivors of early stage endometrial cancer
}

\author{
Bozena Dobrzycka', Robert Terlikowski², Bozena Kulesza-Bronczyk', Jacek Niklinski', \\ Slawomir Jerzy Terlikowski ${ }^{1}$ \\ ${ }^{1}$ Department of Obstetrics, Gynecology and Maternity Care, Medical University, Bialystok, Poland \\ 2 Department of Rehabilitation, Medical University, Bialystok, Poland \\ ${ }^{3}$ Department of Clinical Molecular Biology, Medical University, Bialystok, Poland
}

Dobrzycka B, Terlikowski R, Kulesza-BronczyK B, Niklinski J, Terlikowski S J. Quality of life in long-term survivors of early stage endometrial cancer. Ann Agric Environ Med. 2017; 24(3): 513-516. doi: 10.5604/12321966.1232759

\begin{abstract}
Introduction. Endometrial cancer (EC) is the most common gynaecological malignancy in developed countries. Effective treatment of the early stage of the disease is achieved by surgery alone. An increasing number of patients with EC become long-term survivors; therefore, the purpose of this study was to investigate the quality-of-life (QOL) of EC survivors.

Materials and Method. A total of 328 survivors who had completed cancer treatment more than 3 years ago, and had previously completed questionnaires concerning QOL - European Organization for Research and Treatment of Cancer Quality of Life Questionnaire (EORTC QLQ-C30) and depression - Beck Depression Inventory-II (BDI-II). Patients were grouped into those with surgery alone or surgery with adjuvant radiotherapy. Responses were compared with 284 healthy women who were seen for standard gynaecologic screening examinations.

Results. According to the presented results, the QOL of women with EC after surgical treatment was equal to that of healthy women in the control group. Treatment with adjuvant radiotherapy influenced the QOL, with the exception of emotional functioning $(p=0.028)$. No statistically significant differences were found in scores on the BDI-II between groups for the cognitive-affective factor, the somatic factor, or the total sum score.

Conclusions. The quality of life in EC survivors approximates that of healthy controls after 3 years post-surgical treatment. Patients treated for early stage EC should be informed about the anticipated good prognosis and the low risk of psychosocial and physical long-term effects. Cancer survivors who are treated by surgery and adjuvant radiotherapy may be especially at risk for emotional functioning problems.
\end{abstract}

\section{Key words}

endometrial cancer, quality of life, depression

\section{INTRODUCTION}

Endometrial carcinoma (EC) is the most common gynaecologic malignancy among postmenopausal women in western countries. The age-adjusted incidence rate in the USA is 23.3 per 100,000 women per year. Other regions with age standardized rates in excess of 10 per 100,000 include Europe, Australia and New Zealand, the southern part of South America, and the nations of the Pacific islands. Low rates occur in Africa (Uganda 3.3 per 100,000) and Asia (China 3.8 per 100,000) $[1,2]$. In Poland, the age-adjusted incidence was 14.4 per 100,000 women per year [3].

Most patients who present with an early stage of the disease have an excellent prognosis. For an early stage of the disease, surgery is the treatment of choice. The standard in therapy still remains total abdominal hysterectomy, bilateral salpingo-oophorectomy, and surgical staging, including pelvic and para-aortic lymphadenectomy. While most women with early-stage EC can anticipate a cure with surgery alone, a significant minority of women with deeply invasive or high-grade tumours will experience local, regional, or distant recurrences. Therefore, adjuvant therapies have been proposed, especially for women with early-stage tumours

Address for correspondence: Sławomir Terlikowski, Department of Obstetrics, Gynaecology and Maternity Care Medical University of Białystok, Poland E-mail: sterlikowski@gmail.com

Received: 19 September 2012; accepted: 2 July 2014; first published: February 2017 with atypical histology, such as papillary serous and clear cell carcinomas $[4,5,6]$.

The use of adjuvant radiation therapy has been controversial since randomized trials have demonstrated improvement in local control, without a clear impact on survival [7]. Since the standard procedures have comparable survival rates, patients typically select the procedure that optimizes the QOL. Treatment for EC is often quite morbid and may involve multiple modalities (surgery, radiation and chemotherapy). Postoperative adjuvant radiotherapy in EC is frequently associated with considerable normal tissue injury that may compromise patient QOL such as small and large bowel complications, urinary complications, and vaginal atrophy $[8,9,10,11,12,13]$.

In recent years, a number of studies examining QOL in long-term survivors of EC have been published. The results of these studies indicate that survivors of EC report high levels of QOL, approximately the same levels as the normal population $[10,14,15,16]$.

\section{OBJECTIVE}

The objective of this study was to perform a comparison of the QOL of women with early stage EC who were treated with either surgery alone, or surgery in combination with postoperative pelvic external beam radiotherapy. 


\section{MATERIALS AND METHOD}

Study population. A long-term follow-up assessment of patients with I and II stages of EC treated at the Department of Gynaecology and Septic Obstetrics of the Medical University in Bialystok, and the Department of Gynaecology of the District Hospital in Bialystok between 2000-2008, were included in the study.

A total of 328 EC survivors who had completed cancer treatment more than 3 years ago and had previously completed questionnaires concerning QOL - European Organization for Research and Treatment of Cancer Quality of Life Questionnaire (EORTC QLQ-C30) and depression - Beck Depression Inventory-II (BDI-II). The patients were grouped into those with surgery alone $(n=202)$ or surgery with adjuvant radiotherapy $(\mathrm{n}=126)$. Responses were compared to 284 healthy women who were seen for standard gynaecologic screening examinations.

Instruments. The EORTC QLQ-C30 is a generic QOL measure for cancer patients. It comprises a global health status/QOL, 5 multi-item functional subscales and several single/multi-item symptomatic subscales. Likert scales (1-7 in the global health status subscale and 1-4 in other subscales) are linearly transformed into scores of $0-100$ where higher scores indicate better functional status or worse symptomatic problems. Higher QLQ-C30 scores on the functioning scale and the global QOL scale indicated better functioning or QOL, whereas higher scores on the symptom scales represented a higher level of symptoms or problems in the QLQ-C30. For these items, only scores from eligible respondents were computed. Mean scores and standard deviations (SD) were calculated for the multi-item and single-item scales [17]. The Polish version of the EORTC QLQ-C30 version 3.0 was used, and scored according to the EORTC scoring guidelines [18].

The second edition of the Beck Depression Inventory-II (BDI-II) 22 was used to assess depressive symptoms. The 21item BDI-II is a widely used self-reporting tool for measuring depressive symptoms, corresponding to the Diagnostic and Statistical Manual of Mental Disorders, $4^{\text {th }}$ Edition criteria of depression. The BDI-II scores range from $0-63$, with a score of $\geq 19$ considered to indicate moderate to severe depression [19].

Statistical analysis. Statistical analysis was carried out using Statistica software, version 9.0PL (StatSoft Inc., StatSoft Polska Sp. z o. o., Poland). Data among the 3 different groups was statistically analyzed using the $t$ test for independent variables. Differences in sociodemographic variables between treatment groups were explored with one-way analysis of variance (ANOVA) using the Bonferroni procedure to correct for multiple comparisons.

\section{RESULTS}

Of the 536 consecutive patients who underwent surgery during the study period, 156 were not eligible for the following reasons: death $(n=56)$, address not known $(n=10)$, cancer progression $(n=54)$, and recurrence radically cured $(n=$ 36). Questionnaires were sent to the remaining 380 eligible patients, and $328(86 \%)$ of them returned the completed survey. Age, marital status, education level, BMI, smoking and alcohol consumption were entered as covariates, and the means or percentage shown were adjusted. Characteristics of the study population are shown in Table 1.

Table l. Sociodemographics of the questionnaire respondents according to treatment

\begin{tabular}{|c|c|c|c|c|}
\hline Demographic & $\begin{array}{l}\text { Surgery } \\
(n=202) \\
\text { No. }(\%)\end{array}$ & $\begin{array}{l}\text { Surgery+ Radiotherapy } \\
\qquad(n=126) \\
\text { No. }(\%)\end{array}$ & $\begin{array}{l}\text { Control } \\
(n=284) \\
\text { No. }(\%)\end{array}$ & $\mathrm{p}$ \\
\hline \multicolumn{5}{|l|}{ Age, years } \\
\hline Mean & 62.1 & 60.9 & 62.2 & 0.324 \\
\hline Standard deviation & 11.3 & 10.3 & 9.5 & \\
\hline \multicolumn{5}{|l|}{ Marital status } \\
\hline Married/cohabiting & $150(74.3)$ & $98(77.8)$ & $222(78.2)$ & 0.787 \\
\hline Widowed & $16(7.9)$ & $6(4.8)$ & $14(4.9)$ & 0.184 \\
\hline Divorced & $8(3.9)$ & $8(6.3)$ & $12(4.2)$ & 0.326 \\
\hline Unmarried & $28(13.9)$ & $14(11.1)$ & $36(12.7)$ & 0.824 \\
\hline Patients with children & $152(75.2)$ & $86(68.2)$ & $246(86.6)$ & 0.481 \\
\hline \multicolumn{5}{|l|}{ Employment status } \\
\hline Working & $112(55.4)$ & $58(46.1)$ & $186(65.5)$ & 0.789 \\
\hline Unemployed & $14(7.0)$ & $8(6.3)$ & $24(8.5)$ & 0.925 \\
\hline Retired & $70(34.6)$ & $52(41.3)$ & $70(24.6)$ & 0.911 \\
\hline On sick leave & $6(3.0)$ & $8(6.3)$ & $4(1.4)$ & 0.752 \\
\hline \multicolumn{5}{|l|}{ Education } \\
\hline Primary school & $30(14.8)$ & $22(17.5)$ & $40(14.1)$ & 0.268 \\
\hline Middle-range training & $74(36.7)$ & $42(33.3)$ & $98(34.5)$ & 0.398 \\
\hline University degree & $98(48.5)$ & $62(49.2)$ & $146(51.4)$ & 0.622 \\
\hline \multicolumn{5}{|l|}{ Health behaviors } \\
\hline Smokers & $40(19.8)$ & $26(20.6)$ & $50(17.6)$ & 0.314 \\
\hline $\begin{array}{l}\text { Alcohol consumption, } \\
\text { mean units per week }\end{array}$ & 5.2 & 4.8 & 4.2 & \\
\hline Body mass index, $\mathrm{kg} / \mathrm{m}^{2}$ & 32.4 & 31.1 & 29.7 & $\begin{array}{l}0.622 \\
0.916\end{array}$ \\
\hline
\end{tabular}

There were no statistically significant differences between the examined groups in terms of sociodemographic variables (Tab. 1). The total EORTC QLQ-C30 score was similar in healthy control patients $78.24 \pm 24.36$ vs. $75.57 \pm 18.50$ (surgery group) and $76.64 \pm 22.32$ (surgery and radiotherapy group) in the cancer patients (Tab. 2). There were no significant differences regarding subscales between cancer patients overall and the control group, apart from emotional functioning $(\mathrm{p}<0.05)$.

According to the results obtained, results the QOL of women with EC after surgical treatment was equal to that of healthy women in the control group. Treatment with adjuvant radiotherapy influenced the QOL, with the exception of emotional functioning $(p=0.028)$. No statistically significant differences were found in scores on the BDI-II between groups for the cognitive-affective factor, the somatic factor, or the total sum score.

\section{DISCUSSION}

Although the majority of women survive early stage EC, the treatment almost always requires some medical intervention. The most common treatment protocol is surgery followed by 
Table 2. Scores on QOL and depression in the three examined groups

\begin{tabular}{lcccc}
\hline Measure & $\begin{array}{c}\text { Surgery } \\
(\mathrm{n}=202) \\
\text { Mean } \pm \text { SD }\end{array}$ & $\begin{array}{c}\text { Surgery+ } \\
\text { Radiotherapy } \\
(\mathrm{n}=126) \\
\text { Mean } \pm \mathrm{SD}\end{array}$ & $\begin{array}{c}\text { Control } \\
(\mathrm{n}=284) \\
\text { Mean } \pm \mathrm{SD}\end{array}$ & $\mathrm{p}$ \\
\hline QOL (EORTC QLQ-C30) & $75.57 \pm 18.50$ & $76.64 \pm 22.32$ & $78.24 \pm 24.36$ & 0.273 \\
\hline Global QOL & $17.80 \pm 21.32$ & $19.84 \pm 22.41$ & $18.62 \pm 21.42$ & 0.328 \\
\hline Fatigue & $2.54 \pm 6.28$ & $3.46 \pm 11.06$ & $3.48 \pm 11.36$ & 0.710 \\
\hline Nausea and vomiting & $11.24 \pm 19.42$ & $15.64 \pm 23.94$ & $16.84 \pm 24.38$ & 0.342 \\
\hline Pain & $18.33 \pm 21.22$ & $18.83 \pm 23.80$ & $19.86 \pm 28.23$ & 0.143 \\
\hline Dyspnea & $14.63 \pm 23.40$ & $18.64 \pm 29.20$ & $14.82 \pm 24.66$ & 0.121 \\
\hline Sleep & $3.85 \pm 13.82$ & $7.8 \pm 23.27$ & $4.18 \pm 14.62$ & 0.614 \\
\hline Appetite & $3.43 \pm 13.64$ & $6.45 \pm 21.82$ & $3.44 \pm 12.86$ & 0.125 \\
\hline Constipation & $6.60 \pm 14.90$ & $6.22 \pm 13.94$ & $5.84 \pm 15.67$ & 0.880 \\
\hline Diarrhea & $6.27 \pm 19.33$ & $6.52 \pm 21.41$ & $6.62 \pm 19.61$ & 0.519 \\
\hline Financial impact & $93.23 \pm 12.59$ & $89.56 \pm 23.66$ & $92.58 \pm 16.82$ & 0.706 \\
\hline Physical functioning & $90.46 \pm 20.41$ & $83.70 \pm 21.37$ & $87.22 \pm 24.46$ & 0.823 \\
\hline Role functioning & $84.83 \pm 18.87$ & $57.43 \pm 19.32$ & $84.94 \pm 16.68$ & 0.028 \\
\hline Emotional functioning & $84.86 \pm 19.89$ & $89.82 \pm 15.38$ & $88.90 \pm 17.62$ & 0.445 \\
\hline Cognitive functioning & $93.24 \pm 21.26$ & $90.22 \pm 19.46$ & $91.82 \pm 19.24$ & 0.821 \\
\hline Social functioning & $5.76 \pm 7.47$ & $5.93 \pm 7.59$ & $5.62 \pm 7.24$ & 0.518 \\
\hline Depression (BDI-II) & & & & \\
\hline Cognitive-affective factor & $0.60 \pm 1.21$ & $0.72 \pm 1.13$ & $0.60 \pm 1.14$ & 0.09 \\
\hline Somatic factor & $2.16 \pm 2.24$ & $2.42 \pm 2.69$ & $2.05 \pm 2.19$ & 0.460 \\
\hline
\end{tabular}

adjuvant radiation therapy. Studies investigating the symptom burden in patients with EC have highlighted issues related to treatment. The symptoms comprise psychological morbidity as well as physical morbidity, including late urological and gastrointestinal symptoms following radiotherapy $[13,20$, $21,22,23,24]$.

Until recently, treatment for EC has focused almost exclusively on the prolongation of life, and few research studies have adequately addressed issues related to the QOL $[10,14,15,16]$. Because of the growing number of EC survivors, the QOL has become increasingly important. However, most pertinent studies have focused on the short-term effects of treatment and disease, showing that EC survivors have a reduced QOL early after treatment. In the presented study, overall QOL in EC survivors more than 3 years post-diagnosis was not significantly different from that of healthy women. This result is consistent with longitudinal studies observing that QOL improves over time in gynaecologic cancer survivors $[10,14,15,16]$.

The presented study included a consecutive series of patients with a long follow-up (median 36 months since treatment) who did not experience recurrence or a second primary tumour. The most striking present finding was that the study group reported having a QOL similar to that of members of the control group. Other studies produced similar findings $[10,14,15]$. This effect may be due to a change in a patient's internal standards as a result of adaptation to the limitations associated with the disease or its treatment.

The key challenges for health care professionals providing long-term survivor care are to identify those patients requiring additional help at the point of discharge, or later in survivorship, and to establish the most effective interventions for those long-term survivors with ongoing needs [25]. This study shows that radiotherapy after surgery does not seem to have a significant impact on the QOL in EC survivors. Miller et al. also highlighted the need for assessment of QOL and emotional functioning. These researchers administered questionnaires to 95 patients with gynaecologic cancer at least 6 months after completion of treatment. The questionnaires asked patients to retrospectively rate any emotional symptoms experienced during active treatment. $57 \%$ of patients reported needing help dealing with emotional problems [26]. Capelli et al. suggested that women with primary gynaecologic cancer had QOL scores similar overall to healthy women. Also notable was the fact that women with primary gynaecologic cancer scored lower than healthy women on scales measuring emotional and physical role functioning [27]. Miller et al. compared QOL in disease-free gynaecologic cancer patients and noted that patients treated with surgery only had better overall QOL, probably due to short treatment time and less advanced disease [28]. Thus, on the basis of the presented findings and those reported by others, EC patients undergoing neoadjuvant or adjuvant radiotherapy should be fully informed of the potential impact on QOL of these treatments.

It appears that QOL is most negatively affected from the time of diagnosis through to the completion of treatment. It also appears that QOL is more substantially impaired during treatment of gynaecologic malignancies than during treatment of other cancers. The QOL typically improves after 6-12 months treatment treatment, then stabilizes, and 1-2 years after treatment. Disease free patients report a QOL that is generally equivalent to other cancer survivors and healthy women [29].

The findings of the current study suggest that the majority of long-term EC survivors have good health and do not experience psychological morbidity or large numbers of unmet supportive care needs. For those women with early stage disease, surgery with individualized use of volume directed radiotherapy is curative. A minority of longterm survivors may benefit from ongoing support, and the current study identified potential predictors of unmet supportive care needs. The identification and support of those EC survivors with unmet needs is a key challenge for health care professionals caring for this population [30]. Previous studies have indicated that levels of clinical depression in gynaecologic cancer survivors up to 5 years post-diagnosis are elevated, compared to healthy controls $[8,15,31]$. However, in the present study, depression was not observed. The results overall indicate that levels of depression in EC survivors return to approximately the same level of healthy controls before survivors reach more than 3 years post-diagnosis.

In conclusion, according to the presented results, QOL in EC survivors approximates that of healthy controls after 3 years post-surgical treatment. Patients treated for early stage EC should be informed about the anticipated good prognosis, and the low risk of psychosocial and physical long-term effects. Cancer survivors who are treated by surgery and adjuvant radiotherapy may be especially at risk for emotional functioning problems. 


\section{REFERENCES}

1. Jemal A, Bray F, Center MM, Ferlay J, Ward E, Forman D. Global cancer statistics. CA Cancer J Clin. 2011; 61(2): 69-90.

2. Boyle P, Levin B. World cancer report. Lyon: IARC Press, 2008.

3. Reports based on data of National Cancer Registry. The Maria Sklodowska - Curie memorial Cancer Center, Department of Epidemiology and Cancer Prevetion, National Cancer Registry 2008, http://epid.coi.waw.pl/krn.

4. Dobrzycka B, Terlikowski SJ, Mazurek A, Kowalczuk O, Niklinska W, Chyczewski L, Kulikowski M. Circulating free DNA, p53 antibody and mutations of KRAS gene in endometrial cancer. Int J Cancer. 2010; 127(3): 612-621.

5. Lu KH. Management of early-stage endometrial cancer. Semin Oncol. 2009; 36(2): 137-144.

6. Fagotti A, Ferrandina G, Longo R, Mancuso S, Scambia G. Minilaparotomy in early stage endometrial cancer: an alternative to standard and laparoscopic treatment. Gynecol Oncol. 2002; 86(2): 177-183.

7. Fakiris AJ, Randall ME. Endometrial carcinoma: the current role of adjuvant radiation. J Obstet Gynaecol. 2009; 29(2): 81-89.

8. Donnelly CM, Blaney JM, Lowe-Strong A, Rankin JP, Campbell A, McCrum-Gardner E, Gracey JH. A randomised controlled trial testing the feasibility and efficacy of a physical activity behavioural change intervention in managing fatigue with gynaecological cancer survivors. Gynecol Oncol. 2011 Jun 18. [Epub ahead of print]

9. von Gruenigen VE, Waggoner SE, Frasure HE, Kavanagh MB, Janata JW, Rose PG, Courneya KS, Lerner E. Liefstyle challenges in endometrial cancer survivorship. Obstet Gynecol. 2011; 117(1): 93-100.

10. Becker M, Malafy T, Bossart M, Henne K, Gitsch G, Denschlag D. Quality of life and sexual functioning in endometrial cancer survivors. Gynecol Oncol. 2011; 121(1): 169-173.

11. von Gruenigen VE, Gibbons HE, Kavanagh MB, Janata JW, Lerner E, Courneya KS. A randomized trial of a lifestyle intervention in obese endometrial cancer survivors: quality of life outcomes and mediators of behavior change. Health Qual Life Outcomes 2009; 7: 17.

12. Basen-Engquist K, Scruggs S, Jhingran A, Bodurka DC, Lu K, Ramondetta L, Hughes D, Carmack Taylor C. Physical activity and obesity in endometrial cancer survivors: associations with pain, fatigue, and physical functioning. Am J Obstet Gynecol. 2009; 200(3): 288.e1-8.

13. Bradley S, Rose S, Lutgendorf S, Costanzo E, Anderson B. Quality of life and mental health in cervical and endometrial cancer survivors. Gynecol Oncol. 2006; 100(3): 479-486.

14. Vaz AF, Pinto-Neto AM, Conde DM, Costa-Paiva L, Morais SS, Pedro AO, Esteves SB. Quality of life and menopausal and sexual symptoms in gynecologic cancer survivors: a cohort study. Menopause 2011; 18(6): 662-669.

15. Gonçalves V. Long-term quality of life in gynecological cancer survivors. Curr Opin Obstet Gynecol. 2010; 22(1): 30-35.

16. Courneya KS, Karvinen KH, Campbell KL, Pearcey RG, Dundas G, Capstick V, Tonkin KS. Associations among exercise, body weight, and quality of life in a population-based sample of endometrial cancer survivors. Gynecol Oncol. 2005; 97(2): 422-430.

17. Aaronson NK, Ahmedzai S, Bergman B, Bullinger M, Cull A, Duez NJ, Filiberti A, Flechtner H, Fleishman SB, de Haes JC, et al. The European Organization for Research and Treatment of Cancer QLQ-C30: a quality-of-life instrument for use in international clinical trials in oncology. J Natl Cancer Inst. 1993; 85(5): 365-376.

18. Fayers P, Aaronson NK, Bjordal K, Curran D and Groenvold M on behalf of the EORTC Quality of Life Study Group. EORTC QLQ-C30 Scoring Manual (Third edition). Brussels, EORTC Quality of Life Group, 2001, 86.

19. Beck AT, Steer RA, Ball R, Ranieri W. Comparison of Beck Depression Inventories -IA and -II in psychiatric outpatients. J Pers Assess. 1996; 67(3): 588-597.

20. Klee M, Machin D. Health-related quality of life of patients with endometrial cancer who are disease-free following external irradiation. Acta Oncol. 2001; 40(7): 816-24.

21. Jereczek-Fossa BA, Badzio A, Jassem J. Time without symptoms and toxicity (TWIST) analysis of adjuvant radiation therapy for endometrial cancer. Radiother Oncol. 2004; 72(2): 175-181.

22. van de Poll-Franse LV, Mols F, Essink-Bot ML, Haartsen JE, Vingerhoets AJ, Lybeert ML, van den Berg HA, Coebergh JW. Impact of external beam adjuvant radiotherapy on health-related quality of life for longterm survivors of endometrial adenocarcinoma: a population-based study. Int J Radiat Oncol Biol Phys. 2007; 69(1): 125-132.

23. Herwig R, Bruns F, Strasser H, Pinggera GM, Micke O, Rehder P, Gozzi C, Willich N, Hertle L. Late urologic effects after adjuvant irradiation in stage I endometrial carcinoma. Urology 2004; 63(2): 354-358.

24. Dunberger G, Lind H, Steineck G, Waldenström AC, Nyberg T, alAbany M, Nyberg U, Avall-Lundqvist E. Fecal incontinence affecting quality of life and social functioning among long-term gynecological cancer survivors. Int J Gynecol Cancer 2010; 20(3): 449-460.

25. Harrison SE, Watson EK, Ward AM, Khan NF, Turner D, Adams E, Forman D, Roche MF, Rose PW. Primary health and supportive care needs of long-term cancer survivors: a questionnaire survey. J Clin Oncol. 2011; 29(15): 2091-2098.

26. Miller BE, Pittman B, Strong C. Gynecologic cancer patients' psychosocial needs and their views on the physician's role in meeting those needs. Int J Gynecol Cancer 2003; 13(2): 111-119.

27. Capelli G, De Vincenzo RI, Addamo A, Bartolozzi F, Braggio N, Scambia $G$. Which dimensions of health-related quality of life are altered in patients attending the different gynecologic oncology health care settings? Cancer 2002; 95(12): 2500-2507.

28. Miller BE, Pittman B, Case D, McQuellon RP. Quality of life after treatment for gynecologic malignancies: a pilot study in an outpatient clinic. Gynecol Oncol. 2002; 87(2): 178-184.

29. Pearman T. Quality of life and psychosocial adjustment in gynecologic cancer survivors. Health Qual Life Outcomes 2003; 1: 33.

30. Humeniuk E, Bojar I, Owoc A, Wojtyła A, Fronczak A. Psychosocial conditioning of depressive disorders in post-menopausal women. Ann Agric Environ Med. 2011;18(2):441-445.

31. Simonelli LE, Fowler J, Maxwell GL, Andersen BL. Physical sequelae and depressive symptoms in gynecologic cancer survivors: meaning in life as a mediator. Ann Behav Med. 2008; 35(3):275-284. 